Title: $\quad$ Electrical Communication Between Glucose Oxidase and Different Ferrocenylalkanethiol Chain Lengths

\author{
Author(s): Shai Rubin \\ Georg Bar \\ Russell W. Cutts \\ Jimmy T. Chow \\ John P. Ferraris \\ Thomas A. Zawodzinski, Jr.
}

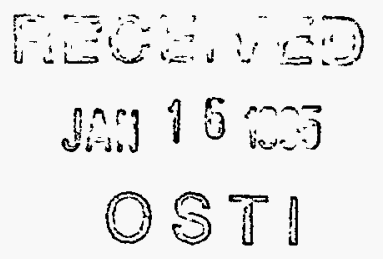




\section{Electrical Communication Between Glucose Oxidase and Different Ferrocenylalkanethiol Chain Lengths}

Shai Rubin*, † Georg Bar*, Russell W. Cutts*, Jimmy T. Chow ${ }^{* *}$, John P. Ferraris ${ }^{* *}$, and Thomas A. Zawodzinski Jr. ${ }^{*}$

*Electronics and Electrochemical Materials and Devices Group, Los Alamos National Laboratory, Los Alamos, NM 87545

** Department of Chemistry, University of Texas/Dallas, Richardson , TX

\section{Abstract}

We describe the factors affecting the electron transfer process between the different components of a self-assembled mixed monolayer. The system is comprised of mixed monolayers containing aminoalkanethiols (AMATs) and ferrocenylalkanethiols (FATs) of variable chain lengths. We study the effects of different ratio of the two mixed monolayer components on the permeability of the monolayer towards a $\mathrm{Ru}\left(\mathrm{NH}_{3}\right)_{6} \mathrm{Cl}_{3}$ redox probe. In order to study the electrical communication between the enzyme and the mediator molecules, the enzyme glucose oxidase (GOx) was attached to the AMAT sites to create a biosensor device. The relative efficiency of a biosensor of each chain-length combination of FAT and AMAT was examined. In light of this comparison, we consider the critical factors for efficient electron transfer between the ferrocene mediator and the GOx redox active site immobilized as part of the surface-confined system. We find that the biosensor response is greatest when the enzyme and the FATs are attached to the surface with different alkane chain lengths. We also find strong evidence for the existence of domains of FAT and AMAT in the mixed monolayer system.

$\dagger$ Present address: Freiburger Materialforschungzentrum, Albert-Ludwigs Universität, Stefan-Meier-Str. 21, 79104 Freiburg, Germany. 


\section{Introduction}

Self-assembly of monolayers of alkane-thiols on gold surface is a promising approach to the creation of well organized nano-structured systems. The sulfur-gold bond is very stable (homolytic bond strength is $\sim 44 \mathrm{Kcal} / \mathrm{mol}$ ), and the monolayer formed is, under favorable conditions, well packed ${ }^{1}$. The fixed length between the gold and the monolayer surface makes such monolayers ideal systems for studying the distance dependence of the heterogeneous electron transfer rate between the electroactive moieties contained in the self-assembled monolayer (SAM) and the gold electrode ${ }^{2}$. SAMs have been extensively characterized with a variety of methods as AFM/STM ${ }^{3}, \mathrm{FTIR}^{4}$, contact angle ${ }^{5}$ and XPS 6 . This enables one to use a well-defined modified gold surface for various fundamental studies 7 . These features of Au/alkane thiol self-assembled monolayers allow a good starting point for the development of a tailored system that has the capability for electronic communication between its components.

Multifunctional mixed monolayers, which contain more than one active functional units, offer a potential method of developing a rich array of device proto-structures. Mixing two components onto the monolayer also contributes to the understanding of the mutual forces between the two components, due to the dense packing of such monolayer. Creager et. al. ${ }^{8}$ studied the shift of the redox potential of ferrocenylhexanethiol (6FAT) in mixed monolayers of 6FAT with alkanethiols (ATs) of various chain lengths. They found that the redox potential of the ferrocene probe depends on the alkanethiol chain length. Because of the rigidity of this monolayer system, it can be used as a model to study hostguest interactions. Zhang et. al. ${ }^{9}$ used mixed monolayers of ferrocenylcarboxyalkanethiol and alkanethiol to examine the interaction between ferrocene (guest) and different calix[6]arenes.

In a previous paper, we described a biosensor system based on a ferrocenylhexadecanethiol (16FAT) and aminoethanethiol (AET) mixed monolayer modified by glucose oxidase $(\mathrm{GOx})^{10}$. We showed that a certain ratio between the components of the mixed monolayer allows us to achieve the best response to different glucose concentrations. We suggested that the distribution of the components of the mixed monolayer is not random, but that there are domains of 16FAT and AET on the electrode. These two facts were manifested by the appearance of two voltammetric waves for the mixed monolayer in the presence of glucose. The two waves corresponded to $\mathrm{Fc}$ interacting with GOx and a non-interacting population of ferrocene. At the 16FAT loading yielding optimal response to glucose, the free ferrocene wave was not observed.

Here we describe the use of FAT:aminoalkanethiol mixed monolayers to act as a catalytic surface effecting the electron transfer process from glucose to the gold electrode 
via the enzyme glucose oxidase (GOx). We studied the influence of different combinations of chain length of the aminoalkanethiol and the ferrocenylalkanethiol on the observed catalytic response to improve our understanding of the critical factors involved in achieving optimal communication between components in such systems.

\section{Experimental section}

Materials: The gold and the titanium purity is $99.999 \%$. Microscope slides were obtained from Corning. Glutaraldehyde was obtained from Fluka, glucose oxidase (GOx) (E.C 1.1.3.4) from Sigma, 16FAT, 12 FAT, 8 FAT, 6 FAT were synthesized according to the procedure that published elsewhere 10 .

Synthesis of 6-aminohexanethiol and 10-aminodecanethiol: A solution of 1, $\omega$ dibromoalkane $\left[\mathrm{Br}\left(\mathrm{CH}_{2}\right)_{\mathrm{n}} \mathrm{Br}\right](\mathrm{n}=5,9), 88.0 \mathrm{mmol}$ in $50 \mathrm{~mL}$ of DMSO was stirred at $75^{\circ} \mathrm{C}$ and $\mathrm{NaCN}$ ( $88.0 \mathrm{mmol}$ ) was added in small portions to keep reaction temperature between $75-85^{\circ} \mathrm{C}$. The solution was refluxed for eight hours, then cooled down and added to $350 \mathrm{~mL}$ of 1:1 mixture of hexanes and ethyl ether. This solution was washed with $3 \times 200 \mathrm{~mL}$ of distilled water and dried over anhydrous magnesium sulfate.

The crude product was purified by column chromatography over silica gel (hexanes: ethyl acetate 3:1) to yield 54-60\% of $\omega$-bromo-alkylnitrile $\left[\mathrm{Br}\left(\mathrm{CH}_{2}\right)_{n} \mathrm{CN}\right]$. Thiourea ( $50 \mathrm{mmol}$ ) was added to the solution of the $\omega$-bromoalkylnitrile $(50 \mathrm{mmol})$ in 85 $\mathrm{mL}$ of dry methanol and the mixture was refluxed for 24 hours. After removing the methanol, aqueous $\mathrm{NaOH}$ solution ( $54 \mathrm{mmol}$ in $40 \mathrm{~mL}$ of distilled water) was added to the reaction vessel and the mixture was refluxed for 12 hours under nitrogen, then cooled down. The reaction mixture was extracted with $150 \mathrm{~mL}$ ethyl acetate, and the organic layer was washed with $3 \times 100 \mathrm{~mL}$ of distilled water, dried over anhydrous magnesium sulfate, and the organic layer was stripped off. The crude material was purified by column chromatography (silica gel, hexanes: ethyl acetate $4: 1$ ) to give the $\omega$-mercaptoalkanenitrile in $65-80 \%$ yield. A solution of the $\omega$-mercaptoalkanenitrile $(35 \mathrm{mmol}$ in $75 \mathrm{~mL}$ of dried ethyl ether) was treated with $70 \mathrm{mmol}$ of $\mathrm{LiAlH}_{4}$. The reaction mixture was stirred for 24 hours under nitrogen then quenched with a mixture of $100 \mathrm{~mL}$ of $2: 1$ cooled distilled water: methanol. The $\omega$-aminoalkanethiol was extracted with $2 \times 100 \mathrm{~mL}$ ethyl ether, dried over anhydrous magnesium sulfate and the solvent was evaporated to give the product in 95-97\% yield.

Electrode fabrication: Gold electrodes ( $2000 \AA$ thick) were prepared by sputter deposition of gold onto glass slides which had been precoated with a film of titanium $(\sim 50$ $\AA$ thick $)^{10}$. The average roughness factor of the glass $/ \mathrm{Ti} / \mathrm{Au}$ electrodes is 1.7 , and was measured by integrating an oxide stripping peak as described by Woods 11 . 
Formation of Monolayers: The electrodes were soaked for $10 \mathrm{~min}$ in concentrated nitric acid, rinsed with distilled water and ethanol and dried with argon.

(a) 16FAT:aminoethanethiol mixed monolayer: The electrodes were soaked in an ethanolic solution of 16FAT (0.09-0.12 mM) and aminoethanethiol (1.9 mM) for 1-6 hours and then transferred to an ethanolic solution of aminoethanethiol (2mM). 12 FAT:aminohexanethiol, 8 FAT:aminodecanethiol, and 6FAT:aminodecanethiol mixed monolayers were prepared similarly.

\section{Result and discussion}

The steps used in formation of the multifuntional SAM on the gold surface, from bare gold electrode to biosensor device, are summarized in figure 1. The object of the first step is to tune the amount of each component in the mixed monolayer. The amine groups of the mixed monolayer are then connected to the enzyme using glutaradehyde as a coupling agent.

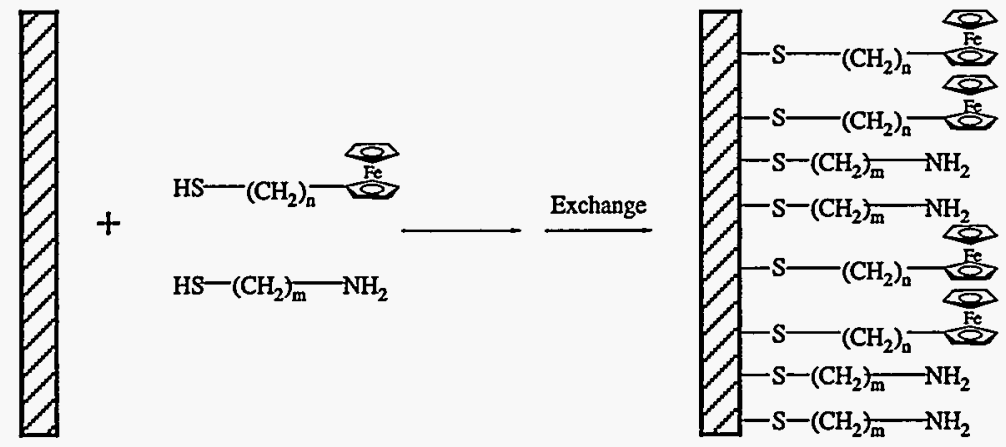

$\mathrm{n}=6,8,12,16 \mathrm{~m}=2,6,10$

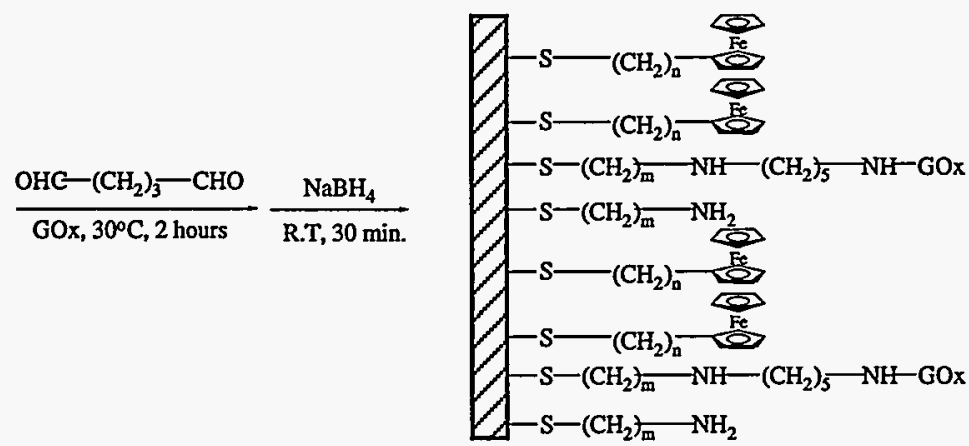

Figure 1: the modification of the gold surface with the biosensor assembly. The first step in the modification of the electrode with ferrocenylalkanethiol and/or the aminoalkanthiol components. The composition is tuned by exchange. The second step is the modification of the mixed monolayer with the enzyme.

We studied four different mixed monolayer systems: 16FAT:aminoethanethiol(AET), (b)12FAT:aminohexanethiol(AHT), (c)8FAT: 
aminodecanethiol (ADT), (d) 6FAT:aminodecanethiol (ADT). These combinations represent a systematic variation of the chain length of the components in the mixed monolayers. A comparison of the calculated spacer lengths for each of the components, i.e between the electrode and the ferrocene or the enzyme after the modification of the mixed monolayer by glutaraldehyde, is shown in Figure 2. For the 16FAT:AET system, the spacer length of the ferrocene is $\sim 20 \AA$, and the spacer of the enzyme is $\sim 10 \AA$ (figure $2 a$ ). Thus, for this combination, it is likely that ferrocene can penetrate into the protein region. In the case of the 12FAT:AHT system, the spacer chain lengths are similar $(\sim 15 \AA$, figure $2 b)$. In this case, the enzyme is placed on the surface of the monolayer. The system 8FAT:ADT has the opposite positioning of enzyme and ferrocene compared to 16FAT:AET case: the spacer length of the ferrocene is $\sim 10 \AA$ while that of the enzyme the length is $\sim 20$ $\AA$ (figure 2c). Figure $2 d$ illustrates an even more drastic example of the 'inverted' positioning of ferrocene and enzyme. In the 6FAT:ADT mixed monolayer system the ferrocene spacer is $\sim 7.5 \AA$ long and the enzyme spacer is $\sim 20 \AA$ long.

a

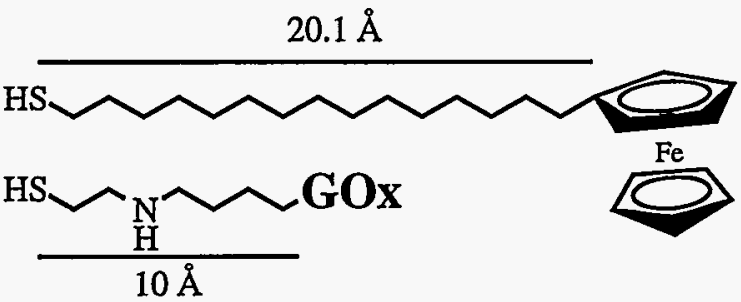

b

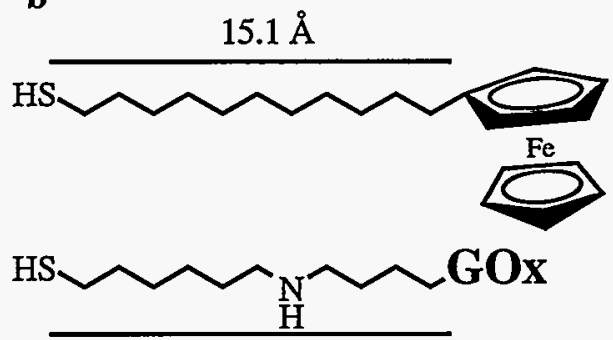

$15 \AA$

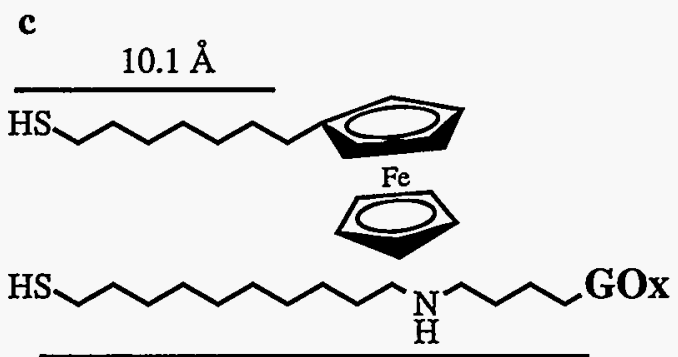

$19.9 \AA$

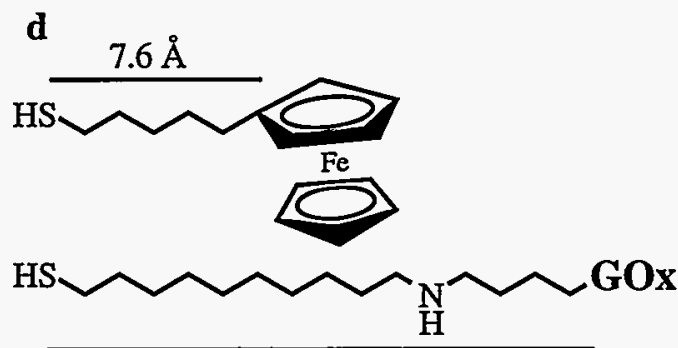

$19.9 \AA$

Figure 2: The spacers between the ferrocene (the above molecule in every couple) or the enzyme (Gox) to the sulfor atom that attached to the electrode.

We studied the different mixed monolayer systems we using $\mathrm{Ru}\left(\mathrm{NH}_{3}\right)_{6} \mathrm{Cl}_{3}$ as a redox probe 12 . This kind of experiments yields information on defect sites in the monolayer due to disordered regions or domains of short chainlength components. We previously 10 showed that we can create, by exchanging the $16 \mathrm{FAT}$ monolayer with AET, holes in the mixed monolayer structure through which $\mathrm{Ru}\left(\mathrm{NH}_{3}\right)_{6} \mathrm{Cl}_{3}$ can penetrate to the 
electrode. From the $\mathrm{Ru}\left(\mathrm{NH}_{3}\right)_{6} \mathrm{Cl}_{3}\left(\mathrm{E}_{0}=-210 \mathrm{mV}\right)$ cyclic voltammogram shape, the mode of diffusion of the redox probe towards the electrode can be deduced.

Figure 3 shows the behavior of mixed monolayers of various chain length combinations in such an experiment. Figure 3a shows that, for a pure 16FAT monolayer $\left(2.6 \times 10^{-10} \mathrm{~mol} / \mathrm{cm}^{2}\right)$, no current can be observed. After lowering the $16 \mathrm{FAT}$ loading to $2.4 \times 10^{-10} \mathrm{~mol} / \mathrm{cm}^{2}$ by AET exchange, only tunneling current can be observed. Further exchange causes more defects in the monolayer: for $16 \mathrm{FAT}$ loading in the range $1.9 \times 10^{-}$

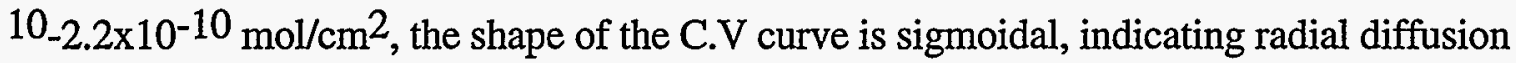
of the redox probe towards the electrode, as for a conventional microelectrode. For a16FAT loading of $0.36 \times 10^{-10} \mathrm{~mol} / \mathrm{cm}^{2}$, the voltammogram shape becomes similar to that characteristic of of semi-infinite linear diffusion. We conclude that the AET exchange process causes the formation of domains of the short amine components, allowing the redox probe to penetrate through them to the electrode.

For longer AMAT chain lengths, hole creation is not expected when FATs are replaced by AMATs. Figure 3b shows the electrochemical response of the $\mathrm{Ru}\left(\mathrm{NH}_{3}\right)_{6} \mathrm{Cl}_{3}$ for a monolayer of $12 \mathrm{FAT}$ progressively replaced by AHT. The neat 12FAT monolayer $\left(2.7 \times 10^{-10} \mathrm{~mol} / \mathrm{cm}^{2}\right)$ does not show any current response at $-210 \mathrm{mV}$. Exchange of the monolayer with AHT to lower the loading of 12FAT to $1.9 \times 10^{-10} \mathrm{~mol} / \mathrm{cm}^{2}$ causes defects in the monolayer as indicated by the observation of a tunneling current. Further exchange to a loading of $1 \times 10^{-10} \mathrm{~mol} / \mathrm{cm}^{2} 12 \mathrm{FAT}$ causes a slightly higher tunneling current; however, further increases in the AHT loading (lowering the12FAT loading to $0.45 \times 10^{-10}$ $\mathrm{mol} / \mathrm{cm}^{2}$ ) lowers the tunneling current, possibly due to improved order in the amine regions. Figure $3 \mathrm{c}$ shows the resultsa for $6 \mathrm{FAT} / \mathrm{ADT}$ mixed monolayers. For a neat $6 \mathrm{FAT}$ monolayer, $\left(1.6 \times 10^{-10} \mathrm{~mol} / \mathrm{cm}^{2}\right)$ a low tunneling current is observed. Exchange to the level of $1.2 \times 10^{-10} \mathrm{~mol} / \mathrm{cm}^{2} 6 \mathrm{FAT}$ increases the tunneling current slightly, but further decreases in $6 \mathrm{FAT}$ laoding down to $0.5 \times 10^{-10} \mathrm{~mol} / \mathrm{cm}^{2} 6 \mathrm{FAT}$ causes a decrease in the tunneling current. The tunneling current of the mixed monolayer with $0.5 \times 10^{-10} \mathrm{~mol} / \mathrm{cm}^{2}$ 6FAT is even lower than for the case of the 6FAT monolayer. In the case of 8FAT:ADT exchange process no current was observed for all compositions studied (in the range of 8FAT loadings $2.4 \times 10^{-10}-0.5 \times 10^{-10} \mathrm{~mol} / \mathrm{cm}^{2}$; data is not shown).

Clearly, the longer amine chain blocks almost completely the penetration of the $\mathrm{Ru}\left(\mathrm{NH}_{3}\right)_{6} \mathrm{Cl}_{3}$ towards the electrode. Improved blocking of the redox probe by the mixed monolayers with the highest percentages of AHT or ADT (figure $3 \mathrm{~b}$ and $3 \mathrm{c}$ ) implies that the adsorption of the AMAT initially causes defects in the monolayer structure but as the exchange process proceeds the AMAT adsorbs in regions already occupied by AMAT, forming more highly ordered domains. 

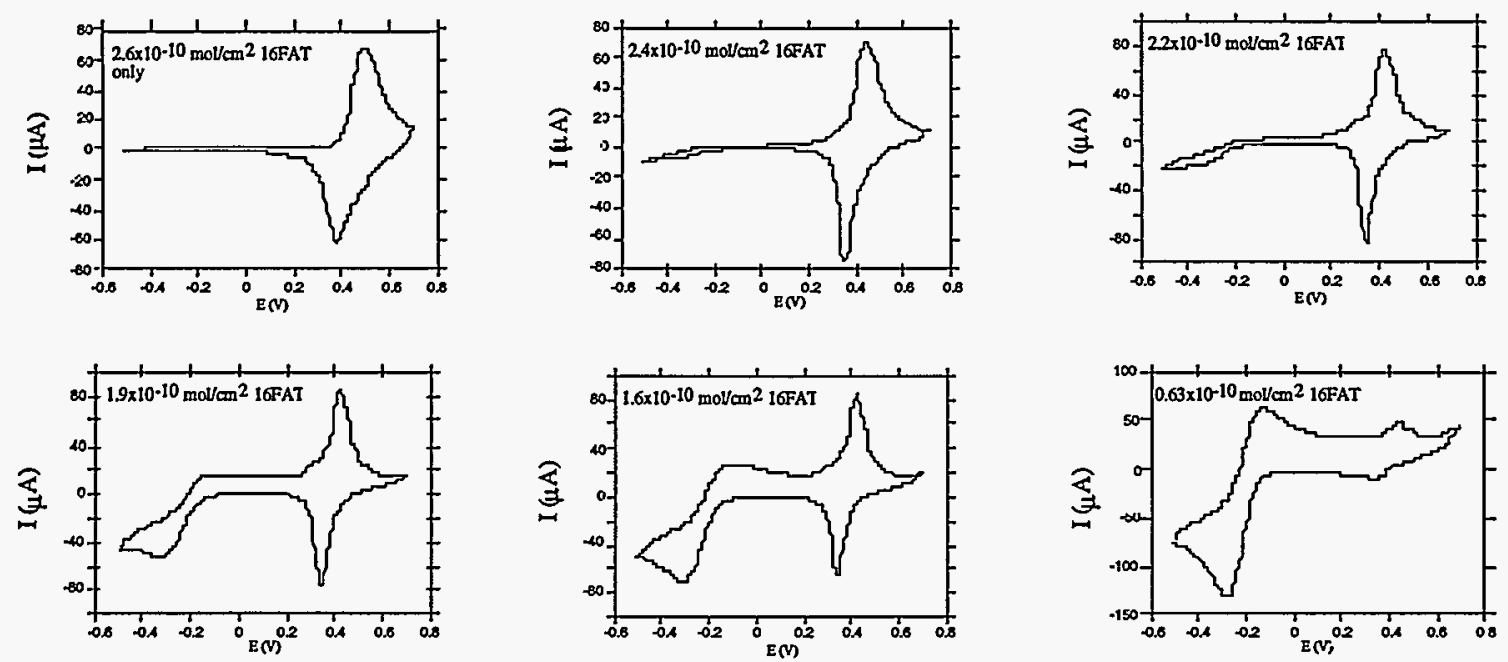

Figure 3a
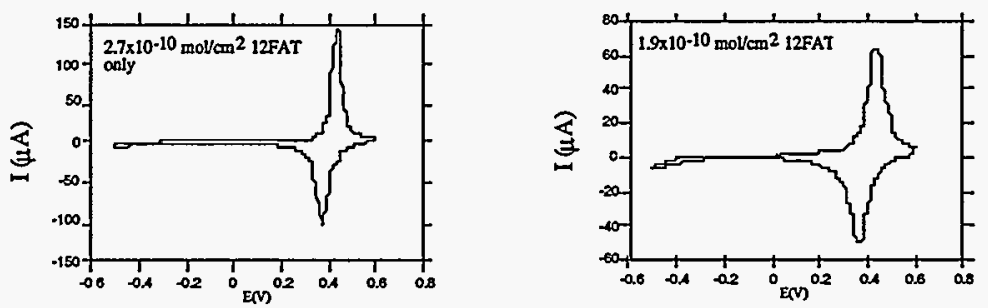

Figure 3b
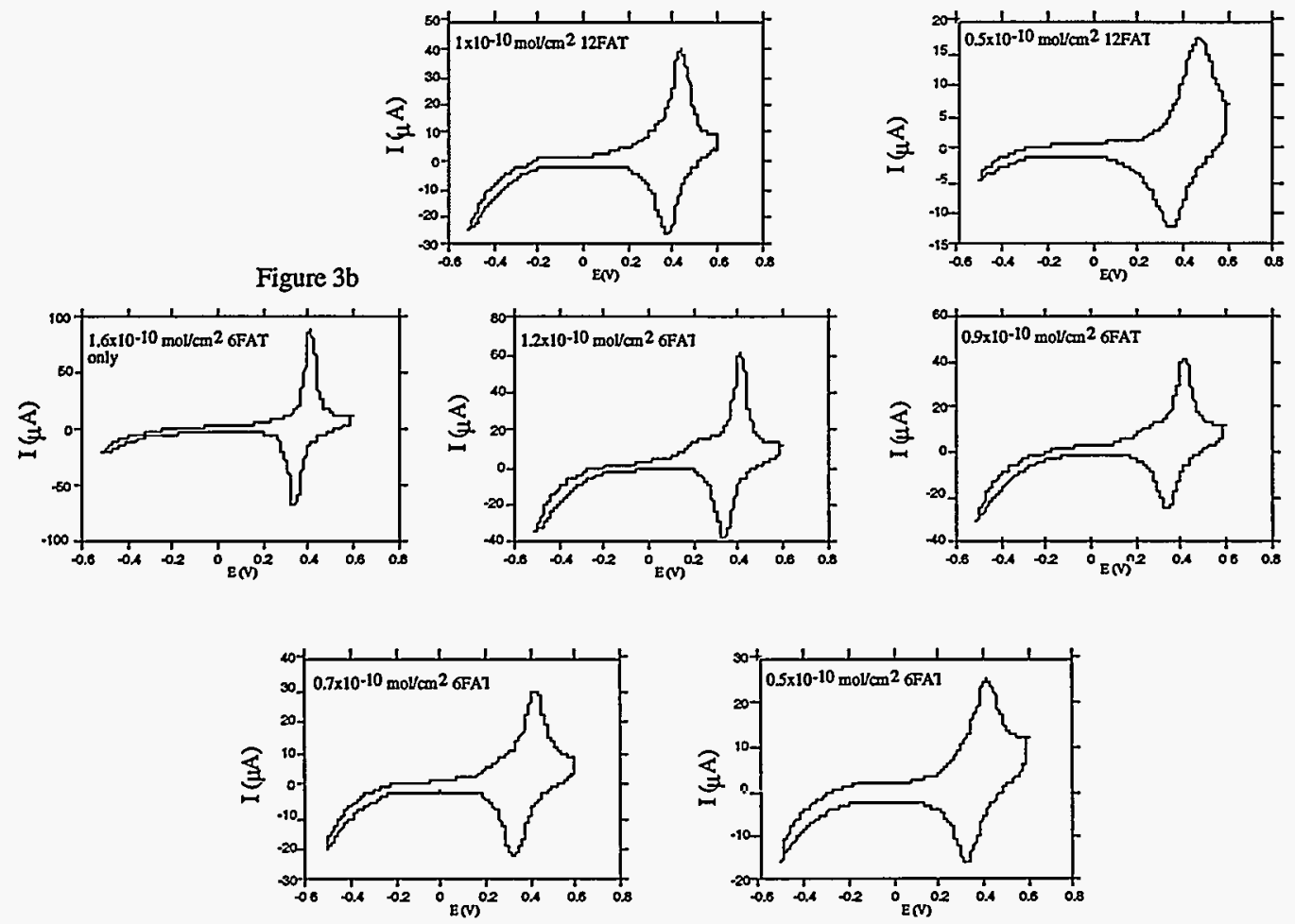

Figure 3c

Figure 3: Amperometric response of the different mixed monolayer systems, with different loadings of

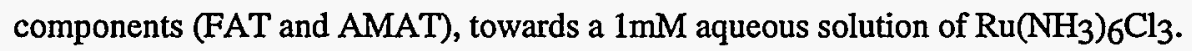


We previously reported the use of the mixed monolayer system of 16FAT and AET modified by GOx to function as a biosensor for glucose ${ }^{10}$. We designed this system based on the assumption that, for such a combination component chain lengths, the ferrocene will be able to act as an electron shuttle between the enzyme redox site and the electrode due to the mobility that the mediator molecule has in such mixed monolayers. Figure 4a shows that, indeed, for this combination there is an amperometric response of the system to changes in glucose concentration. The optimal loading of 16FAT, i.e. that leading to the most sensitive amperometric response, is $3.2 \times 10^{-11} \mathrm{~mol} / \mathrm{cm}^{2}$ 16FAT (figure $4 \mathrm{a}$, curve i). The remainder of the adsorbed monolayer is aminoethanethiol. The amperometric response of the systems with higher 16FAT loading (Figure 4a, curves ii and iii) is smaller because the amount of the amine component is lower, leading to a reduced loading of enzyme near the mediator. This is manifested in the appearance of a wave due to noninteracting ferrocene in the voltammogram of monolayers with more 16FAT than optimal .

We wanted to learn more about the electron transfer process between the mediator surface and the enzyme active site. In the 12FAT:AHT system, the chain length of the ferrocene spacer and the enzyme spacer are equal (figure $2 b$ ). Therefore this mixed monolayer system is expected to be quite rigid, i.e. we expect little ability of the components to adjust their positions to achieve effective interactions. Figure $4 \mathrm{~b}$ shows the amperometric response of this system towards different glucose concentrations. In this system the mediation efficiency ${ }^{\#}$ of the ferrocene is $\sim 12 \%$ (for the best composition, $3.2 \times 10^{-11} \mathrm{~mol} / \mathrm{cm}^{2}$ of $12 \mathrm{FAT}$, figure $4 \mathrm{~b}$ curve i) that of the 16FAT:AET system. Figure 5 shows a schematic explanation of the activity difference in these two systems. Figure $5 \mathrm{a}$ shows the 12FAT:AHT system after the modification of the monolayer with GOx using glutaraldehyde as a spacer. The electrical communication in this system is hindered relative to that in the system of 16FAT:AET (Figure 5b). In the 12FAT:AHT system, the enzyme and mediator reside at the monolayer/water interface. Direct electro-communication between the electrode and the redox center of GOx is not straight forward ${ }^{13}$ and the and the enzyme and mediator cannot easily achieve positioning allowing them to interact.

The next system that we studied is 8 FAT:aminodecanethiol. In this system, the mediator is buried in the mixed monolayer and the enzyme is somewhat separated from the monolayer surface (figure $2 \mathrm{c}$ ). Figure $4 \mathrm{c}$ shows the amperometric responses of electrode surfaces modified with various proportions of the two components. The sensitivity is better then the sensitivity of the 12FAT:AHT system but it is still only 40\% (for the

\footnotetext{
\# Mediation efficiency: The catalytic response of any system $105 \mathrm{mM}$ of glucose, compare to the catalytic response of the system 16 FAT:aminoethanethiol at 105 $\mathrm{mM}$ of glucose.
} 
optimal composition, $8.5 \times 10^{-11} \mathrm{~mol} / \mathrm{cm}^{2} 8 \mathrm{FAT}$ loading, figure $4 \mathrm{c}$, curve i) that of the 16 FAT:AET system. Because the enzyme has to penetrate into the mixed monolayer to react with the mediator molecule, the amperometric response of this system is somewhat surprising if we think of this system as a mixed monolayer with random distribution of the two components. In this system the enzyme spacer is $\sim 10 \AA$ longer then the ferrocene spacer; thus, the enzyme is no longer situated on the monolayer/water interface. It can bend towards the ferrocene domain. It is known ${ }^{14}$ that FAD sites of GOX are not centered in the protein shell and was previously shown ${ }^{14}$ that the FAD groups can interact even with metal electrode if the enzyme is as short distance as possible from the electrode. Thus, the chance that the enzyme will be in the right conformation for electron transfer via the mediator is much higher than for the 12FAT:AHT system.

To check this hypothesis, we used the 6FAT:ADT mixed monolayer system (Figure 5c). Figure 4d shows the amperometric response of the system 6FAT:ADT modified by GOx. In this case the mobility of the enzyme spacer is even larger then in the case of 8FAT:ADT, because of the large difference between the length of the two spacers (figure $2 \mathrm{~d}$ ). Indeed, the response of this system (at $6.3 \times 10^{-11} \mathrm{~mol} / \mathrm{cm}^{2} 6 \mathrm{FAT}$ loading degree, figure $4 \mathrm{~d}$, curve i) is the most similar $(\sim 80 \%)$ to the $16 \mathrm{FAT}$ :AET system.
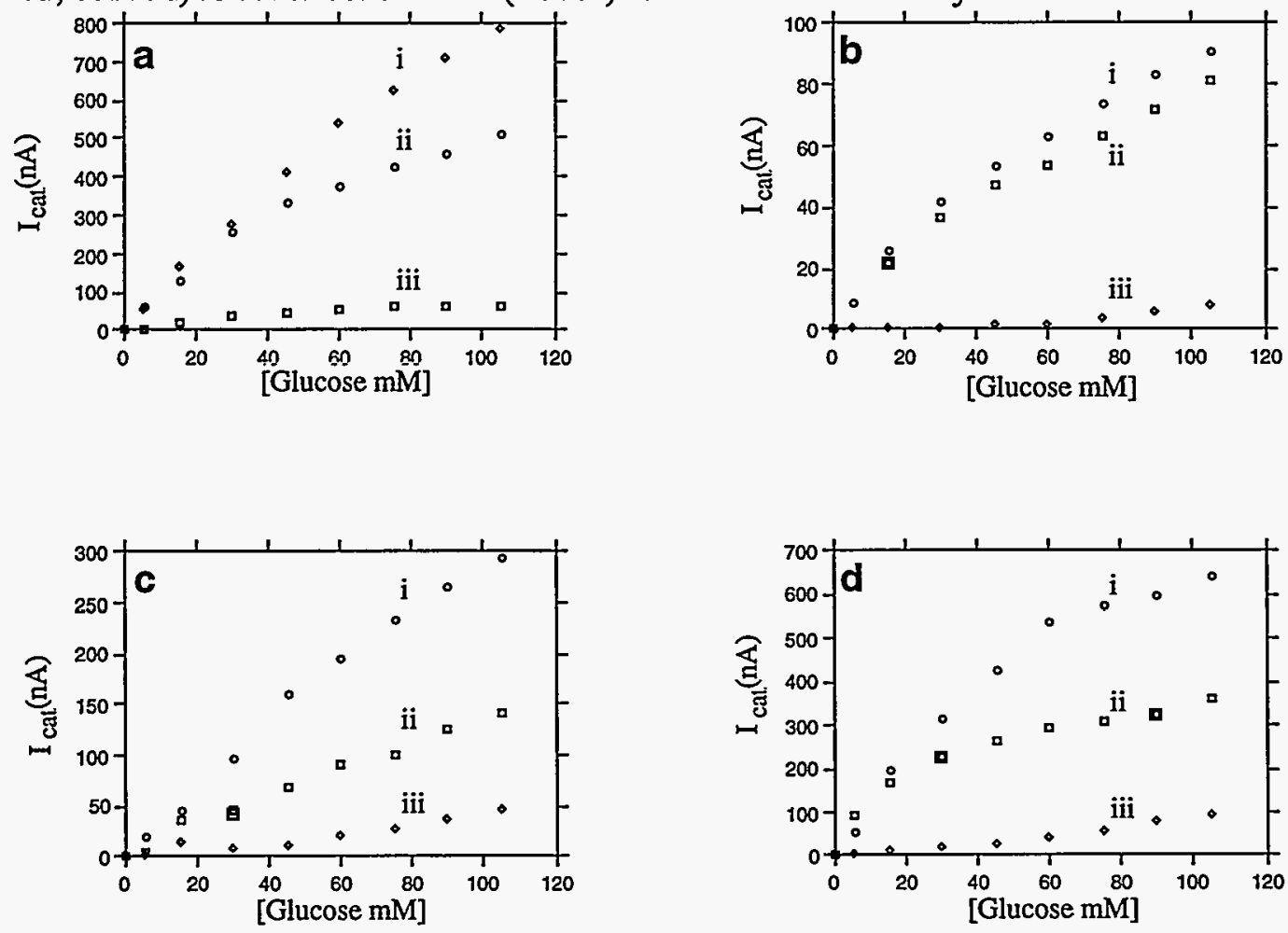

Figure 4: The catalytic response of Gox modified mixed monolayer: a)16FAT:AET, b)12FAT:AHT, c) 8FAT:ADT, d) 6FAT:ADT towards different concentrations of Glucose. 


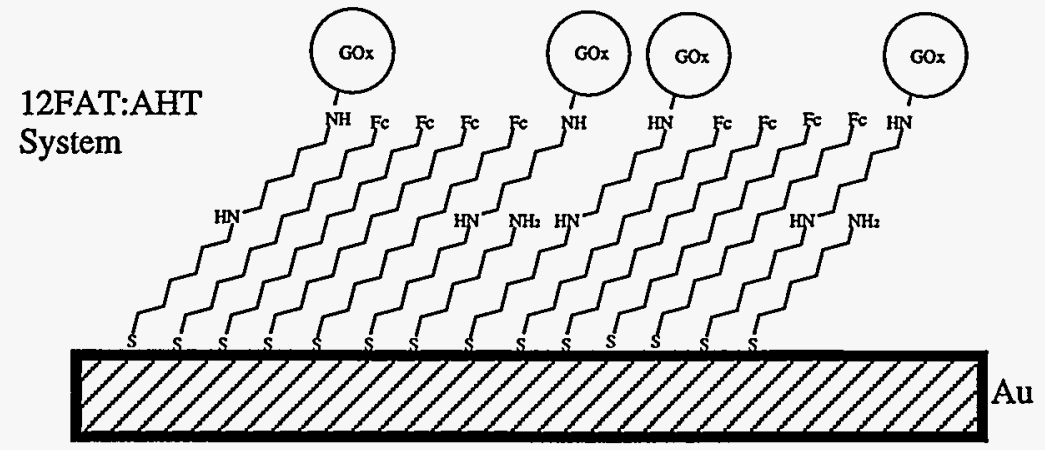

a

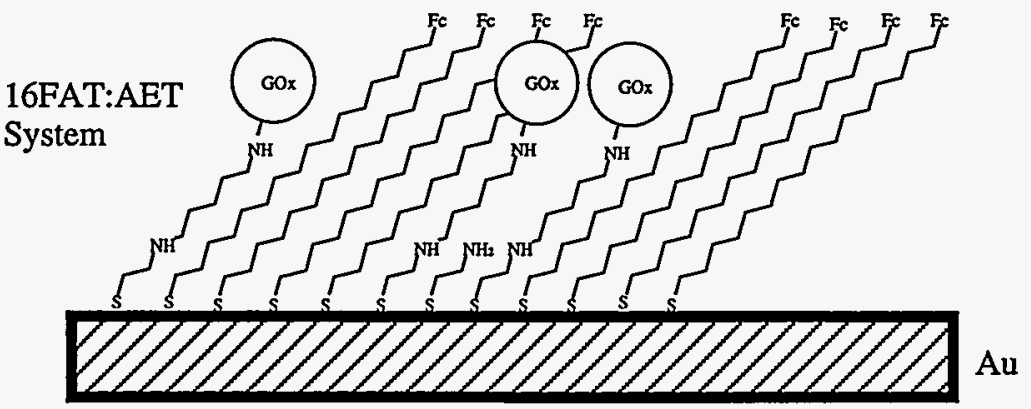

b

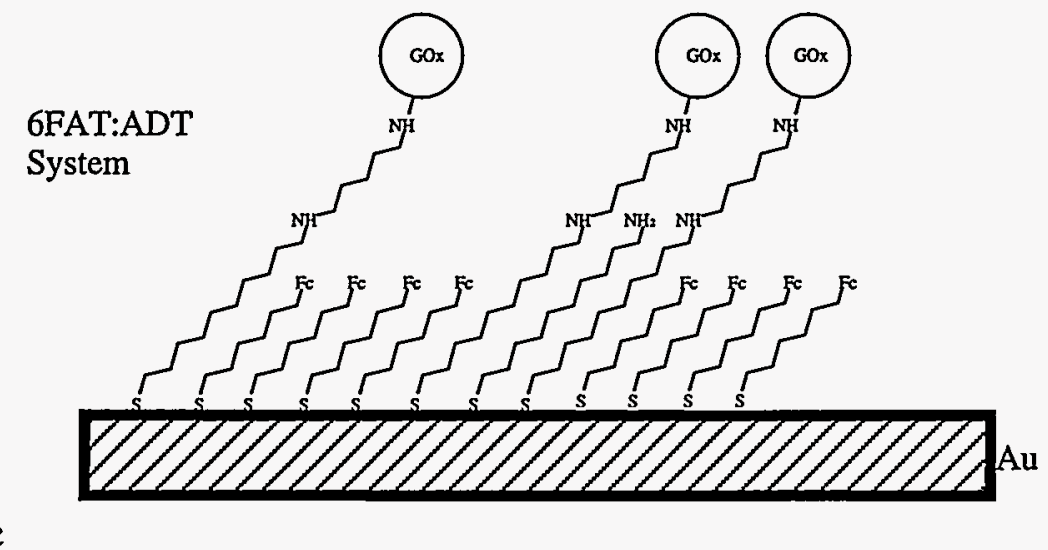

Figure 5: Schematic representation of the different biosensor systems.

\section{Conclusion}

We conclude that the critical factor controlling the electron transfer step in these systems is ability of the enzyme and electron transfer mediator to approach each other. When at least one of the components (the FAT or the enzyme) is mobile, the electron transfer process is possible. However, when the system allows little structural accomodation, as in the case of the 12 FAT:AHT mixed monolayer, the efficiency of the electron transfer between the enzyme and the mediator is poor. Though it is hard to imagine that the enzyme molecule can penetrate through the FAT region to reduce the distance between the active site and the 
mediator when the alkane chain of the FAT is short, it is nonetheless possible that the enzyme can interact with the mediator on the surface in a more favorable conformation for the electron transfer process in a flexible system than in the case when the system is rigid. We also showed that that these mixed monolayer are not randomly ordered, but rather domains of FAT and domain of AMAT are present. Further studies of such domains are in progress in our laboratory.

\section{References}

1. (a) Sellers, H.; Ulman, A.; Shnidman, Y.; Eilers, J.E. J. Am. Chem. Soc. 1993, 115, 9389.

(b) Dubios, L.H.; Nuzzo, R.G. Annu. Rev. Phys. Chem. 1992, 43, 437.

2. Chidsey, C.E.D. Science 1991, 251, 919.

3. (a) Poirier, G.E.; Tarlov, M.J. Langmuir 1994, 10, 2853.

(b) Delamarche, E.; Michel, B.; Gerber, Ch.; Anselmetti, D.; Guntherodt, H.-J.; Wolf, H.; Ringsdorf, H. Langmuir 1994, 10, 2869.

(c) Widring, C.A.; Smith, E.L; Porter, M.D. J. Am. Chem. Soc. 1991, 113, 2805.

(d) Alves, C.A.; Smith, E.L.; Porter, M.D. J. Am. Chem. Soc. 1992, 114, 1222.

4. (a) Shimaza, K.; Ye, S.; Sato, Y.; Uosaki, K. J. Electroanal. Chem. 1994, 375, 409.

(b) Walezak, M.M; Chung, C.; Stole, S.M.; Cindra, A.; Porter, M.D. J. Am. Chem. Soc. 1991, 113, 2370.

(c) Wolf, M.O; Fox, M.A. J. Am. Chem. Soc. 1995, 117, 1845.

(d) Crooks, R.M; Xu, C.; Sun, L.; Hill, S.L.; Ricco, A.J. Spectros. 1993, 8, 28.

(e) Xu, C.; Sun, L.; Kepley, L.J.; Crooks, R.M; Ricco, A.J. Anal. Chem. 1993, 65, 2102.

5. (a) Whitesides, G. M.; Laibinis Langmuir 1990, 6, 87

(b) Ferguson, G.M.; Chaudhury, M.K.; Biebuyck, H.A.; Whitesides, G. M. Macromolecules 1993, 26, 5870.

(c) Lee, T.R., Carey, R.I, Biebuych, H.A; Whitesides, G.M. Langmuir 1994, 10, 741.

6. (a) Nuzzo, R.G.; Fusco, F.A; Allara, D.L J. Am. Chem. Soc. 1987, 109, 2358.

(b) Laibinis, P.E.; Whitesides, G.M; Allara, D.L.; Tao, Y.-T; Parikh, A.N.;

Nuzzo, R.G. J. Am. Chem. Soc. 1991, 113, 7152.

(c) Creager S.E.; Collard, D.M.; Fox, M.A. Langmuir 1990, 6, 1617.

7. Guo, L.-H.; Facci, J.S; Mclendon, G.; Mosher, R. Langmuir 1994, 10, 4588. 
8. (a) Rowe, G.K.; Creager, S.E. Langmuir 1991, 7, 2307.

(b) Rowe, G. K; Creager, S. E. J. Phys. Chem. 1994, 98, 5500.

(c) Creager, S. E.; Rowe, G. K. Anal. Chim. Acta 1991, 246, 233.

(d) Creager, S. E.; Rowe, G. K. Langmuir 1993, 9, 2330.

9. Zhang, L.; Godinez, L.A.; Lu, T.; Gokel, G.W.; Kaifer, A.E. Angew. Chem. Int. Ed. Engl. 1995, 34, 235.

10. Rubin, S.; Chow, J.T; Ferraris, J.P.; Zawodzinski, T.A.Jr. Langmiur, in press.

11. Woods, R. Electroanalytical Chemistry, Vol 9; Bard, A. J. ed.; Marcel Dekker, Inc.; New York and Basel, 1976; p 119.

12. Chailapakul, O.; Crooks, R. C. Langmuir 1993, 9, 884.

Sun, S.; Crooks, R. C. Langmuir 1993, 9, 1951.

Chidsey, C. E. D.; Loiacono, D. N. Langmuir 1990, 6, 682.

Bilewicz, R.; Majda, M. Langmuir 1991, 7, 1951.

Ross, C. B.; Sun, S.; Crooks, R. C. Langmuir 1993,9, 632.

Zhang, L.; Lu, T.; Gokel, G. W.; Kaifer, A. E. Langmuir 1993, 9, 786.

13. Heller, A. J. Phys. Chem, 1992, 96, 3579.

Degani, Y.; Heller, A. J. Phys. Chem. 1987, 91, 1285.

Schumann, W.; Ohara, T. J.; Schmidt, H.-L.; Heller, A. J. Am. Chem. Soc. 1991, 113, 1394.

Degani, Y.; Heller, A. J. Am. Chem. Soc. 1988, 110, 2615.

14. Willner, I.; Riklin, A.; R. Blonder; Katz, E. manuscript in preparation. 